NISSUNA UMANA INVESTIGAZIONE SI PUO DIMANDARE VERA SCIENZIA S'ESSA NON PASSA PER LE MATEMATICHE DIMOSTRAZIONI LEONARDO DA VINCI

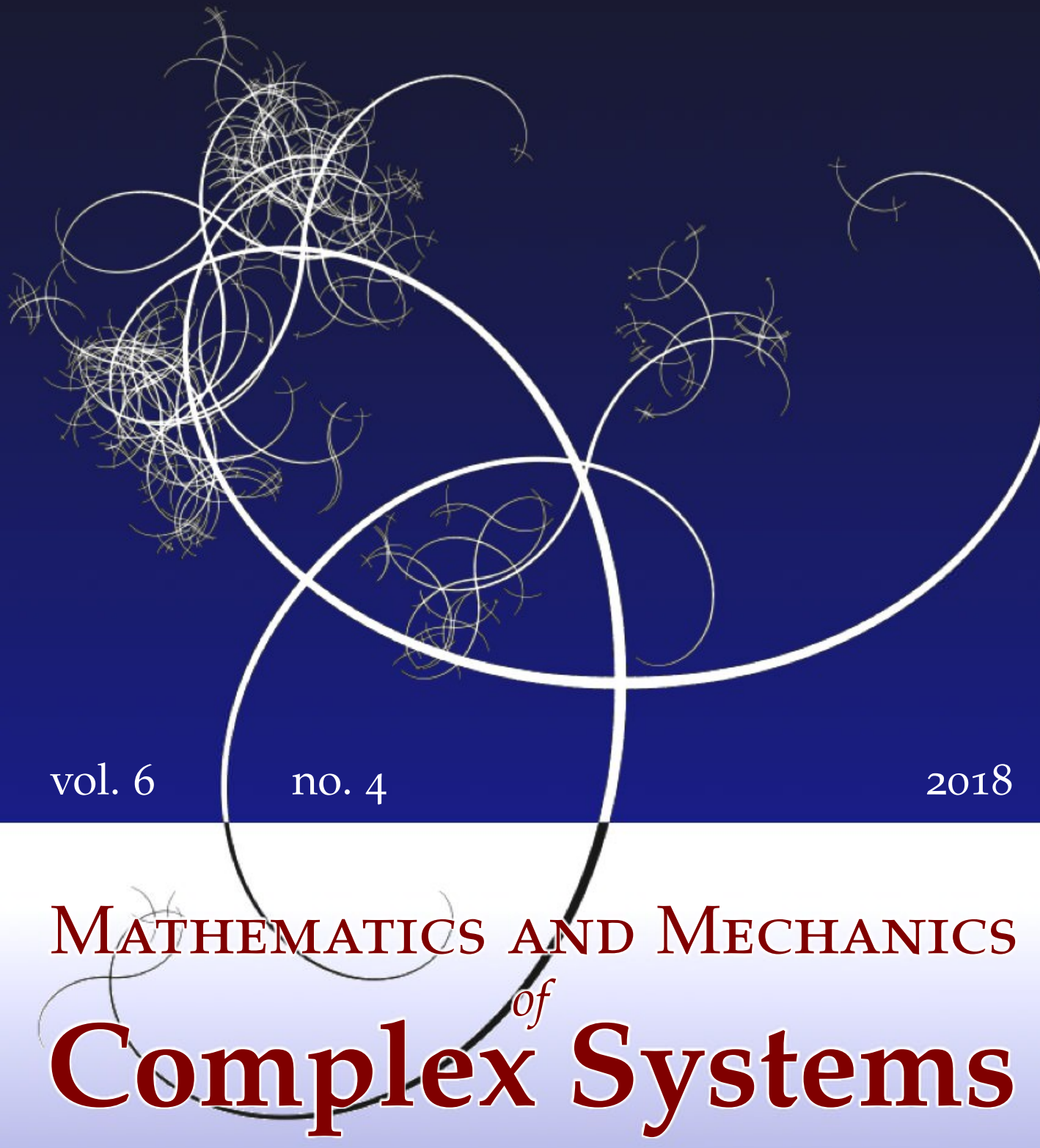

RaChele Allena And Christophe Cluzel

HETEROGENEOUS DIRECTIONS OF ORTHOTROPY

IN THREE-DIMENSIONAL STRUCTURES:

FINITE ELEMENT DESCRIPTION BASED

ON DIFFUSION EQUATIONS 


\title{
HETEROGENEOUS DIRECTIONS OF ORTHOTROPY IN THREE-DIMENSIONAL STRUCTURES: FINITE ELEMENT DESCRIPTION BASED ON DIFFUSION EQUATIONS
}

\author{
RaChele Allena And Christophe Cluzel
}

\begin{abstract}
Heterogeneous materials such as bone or woven composites show mesostructures whose constitutive elements are all oriented locally in the same direction and channel the stress flow throughout the mechanical structure. The interfaces between such constitutive elements and the matrix are regions of potential degradations. Then, when building a numerical model, one has to take into account the local systems of orthotropic coordinates in order to properly describe the damage behavior of such materials. This can be a difficult task if the orthotropic directions constantly change across the complex three-dimensional geometry as is the case for bone structures or woven composites. In the present paper, we propose a finite element technique to estimate the continuum field of orthotropic directions based on the main hypothesis that they are mainly triggered by the external surface of the structure itself and the boundary conditions. We employ two diffusion equations, with specific boundary conditions, to build the radial and the initial longitudinal unit vectors. Then, to ensure the orthonormality of the basis, we compute the longitudinal, the circumferential, and the radial vectors via a series of vector products. To validate the numerical results, a comparison with the average directions of the experimentally observed Haversian canals is used. Our method is applied here to a human femur.
\end{abstract}

\section{Introduction}

In order to simulate the mechanical behavior of heterogeneous structures such as bone or composites, computed tomography (CT) or $\mu \mathrm{CT}$ images allow one to build their three-dimensional (3D) real and complex geometries [Rémond et al. 2016] and the associated finite element (FE) meshes. Nonetheless, there exist only a few numerical tools able to describe a continuum field of anisotropic directions varying throughout the 3D structure.

\section{Communicated by Francesco dell'Isola.}

MSC2010: 00AXX.

Keywords: orthotropic materials, cortical bone, diffusion equations. 
Here, we propose an approach which enables one to estimate via an FE technique the directions of orthotropy (i.e., longitudinal, circumferential, and radial) in 3D structures, which may be compared to beams, assuming that the orthotropy of their mesostructure is mainly triggered by their external surface and the boundary conditions. Such a method is based on [Allena and Aubry 2011], in which a system of Laplacian equations is employed to define the orientation of the cylindrical coordinates across 3D thin membranes. To support the numerical results, a comparison with $\mu \mathrm{CT}$ obtained with data is performed. In [Cluzel and Allena 2015], we applied our method only to a femoral diaphysis, while here the whole 3D cortical domain of a human femur is considered. Additionally, we validate our numerical approach by comparing it to the experimental data previously obtained in [Cluzel and Allena 2018].

1.1. Cortical bone anisotropy. Cortical bone shows a very significant anisotropy at different scales [Rho et al. 1998], and as described in [Rho 1996; Bernard et al. 2013], at the macroscale the elastic behavior is orthotropic. Additionally, microcracks seem to be involved at each length scale as a function of the loading (i.e., tension, compression, or torsion) and to trigger the damage mechanics of bone, although they are described in a local system of coordinates linked to the main directions of the mesostructure [Vashishth 2007].

In [Herman et al. 2010], two types of mechanical degradation of the cortical bone are described: one is linked to linear microcracks, which are 10 to $100 \mu \mathrm{m}$ long, and the other is a set of diffused microcracks, which are 1 to $2 \mu \mathrm{m}$ long. In [SerefFerlengez et al. 2015] these two networks are still observed, but the authors suggest that only the linear microcracks influence the evolution of the elastic behavior of the cortical bone and may be involved in the remodeling process.

At this level, the osteons play an important role and more particularly the cement line appears to be a weak interface likely to stop or divert the microcracks [O'Brien et al. 2007]. From a quantitative point of view, Wasserman et al. [2008] showed that microcracks are almost parallel to the osteons and this is independent from the age of the specimen. Given such a scenario, to describe the degradation or the failure behavior of the cortical bone, one may employ anisotropic criteria which are associated to specific mechanisms. For instance, in [Doblaré et al. 2004; Cowin and $\mathrm{He} 2005$ ] anisotropic and macroscopic criteria are presented, some of them based on approaches that have been previously developed for composites [Tsai and $\mathrm{Wu}$ 1971]. Similarly, the fracture toughness is anisotropic and linked to the osteons' direction [Ural and Vashishth 2007].

Although it has been shown that to precisely describe the global response of a bone structure to different loadings it is necessary to take into account the orthotropic behavior of the cortical bone, many authors still use an isotropic elastic 
model or adopt isotropic failure criteria such as von Mises. In [Bessho et al. 2009; Duchemin et al. 2008], the objective is to localize the fractures and to do so the constitutive behavior of the bone is described as isotropic and heterogeneous. Báča et al. [2008] showed that an isotropic, elastic, and heterogeneous model allows proper quantification of the global displacements of a femur. Nevertheless, for an accurate description of the stress in the case of nonphysiological loads (i.e., prosthesis) or in order to obtain a better understanding of the damage mechanisms, the anisotropy of the bone must be taken into account.

From a numerical point of view, the employment of an orthotropic model remains rather difficult since two main challenges arise: the higher number of material parameters to be introduced and the description of the field of orthotropic coordinates throughout 3D complex geometries. Nonetheless, a few attempts can be found in the literature.

In [Peng et al. 2006], for both spongy and cortical bone, a transversely isotropic model is employed and the local systems of coordinates are described with respect to the superior-inferior axis of the structure without taking into account the potential variations in the neck or in the head. In [Taylor et al. 2002] or [Ün and Çalık 2016], the femoral diaphysis is described as an orthotropic material in a cylindrical coordinate system. Additionally, Ün and Çalık [2016] employ a discrete description of the orthotropic field via a finite number of subvolumes in the diaphysis. In [Báča et al. 2008], the macroscopic bone mesh is manually decomposed into small domains in order to take into account the anisotropy directions detected in vitro. Hambli et al. [2012] proposed an orthotropic damage model to describe the mechanical behavior of the proximal spongy domain of the femur in two dimensions. The orthotropic directions are associated to the principal stress directions obtained through a previous simulation involving a compression load on the top of the femur. A further approach can be found in [Doblaré and García 2001; Gómez-Benito et al. 2005] where the orientation of the orthotropic coordinates is continuously updated thanks to a remodeling model [García et al. 2001]. The simulation runs until the orthotropy directions coincide with the principal stress directions for a typical physiological load. Finally, in [Spingarn et al. 2017], anisotropy is also considered via a remodeling model, but at the mesoscale and in trabecular bone.

As mentioned earlier, in this paper we propose an FE method to approximate the orthotropic field of 3D structures such as the human femur. In the following sections we describe the numerical approach used to build the field of orthotropic directions. In Section 2.1, the segmentation technique adopted to obtain the femur 3D geometry (Section 2.1.1) as well as the diffusion equations employed to determine directions of orthotropy numerically (Section 2.1.2) are detailed. The main results are presented and compared to the experimental data obtained in [Cluzel and Allena 2018] in Section 3. In Section 4, we discuss our numerical outcomes with 


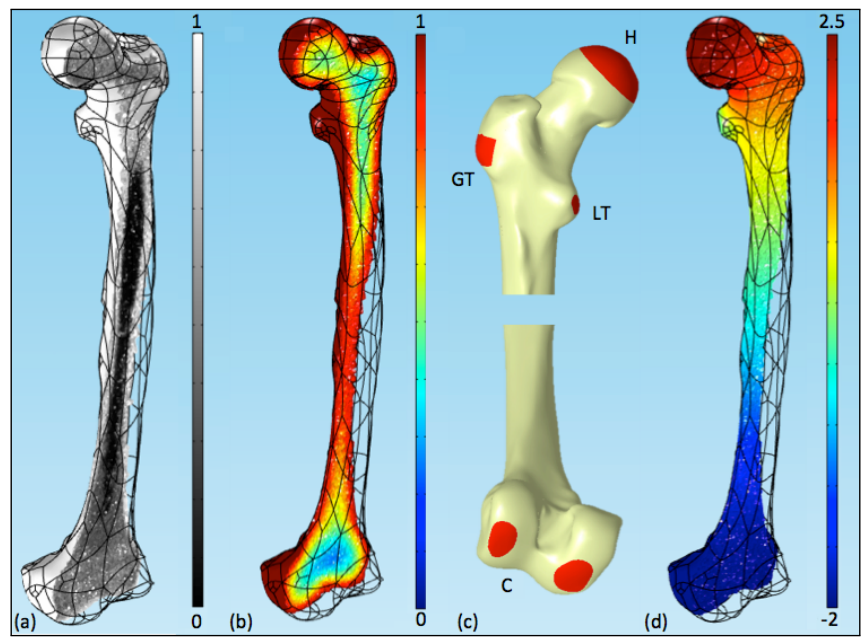

Figure 1. Sagittal sections of the femur showing the gray level (a) and the concentrations of $u_{3}$ (b) and $u_{10}$ (d), and boundary conditions for the diffusion problem providing the unit longitudinal vector $\nabla u_{10}$ (c).

respect to previous works in the literature and some limitations and perspectives of the work are also considered.

\section{Material and methods}

\subsection{FE approximation of the orthotropic field.}

2.1.1. $3 D$ personalized geometry of the femur. A left human male femur (91 years old) was collected and frozen at $-20^{\circ}$ in a plastic bag. Once defrosted, the femur was cleaned by a clinician to remove soft tissues around it and dried with ethanol. Then, it was CT-scanned with a calibration phantom by a GE LightSpeed Pro 16 at pixel spacing of $0.875 \mathrm{~mm}$ and slice thickness of $1.25 \mathrm{~mm}$. CT scans provided the normalized gray level (GL) values varying between 0 and 1 .

The femur has been semiautomatically segmented in Avizo to find its external surface and to mesh the 3D volume in CoMsol Multiphysics (Figure 1(a)). Additionally, by defining a specific threshold on the GL, here fixed at 0.7 , it has been possible to write two characteristic functions ( $h_{\text {cort }}$ and $h_{\text {spong }}$ ) to distinguish between the cortical ( $\left.\Omega_{\text {cort }}\right)$ and the spongy $\left(\Omega_{\text {spong }}\right)$ 3D FE domains:

$$
\begin{aligned}
h_{\text {cort }} & = \begin{cases}1 & \text { if } \mathrm{GL} \geq 0.7, \\
0 & \text { otherwise },\end{cases} \\
h_{\text {spong }} & = \begin{cases}1 & \text { if } \mathrm{GL}<0.7, \\
0 & \text { otherwise } .\end{cases}
\end{aligned}
$$


Some artifacts induced by the presence of remaining soft tissues or due to unexpected porosities may be found on the external femoral surface. Nevertheless, in order to ensure a minimal amount of cortical bone, the GL values have been automatically set to 1 across a thickness of $0.5 \mathrm{~mm}$ from the external surface of the femur to the inner volume.

2.1.2. Numerical technique to determine the main orthotropy directions. In this section, the technique used to determine the numerical system of orthotropic coordinates $R_{\mathrm{FE}}=\left\{\boldsymbol{i}_{1}, \boldsymbol{i}_{2}, \boldsymbol{i}_{3}\right\}$ is detailed. We adopt and adapt a method previously proposed in [Allena and Aubry 2011]. Such an approach was first used to parametrize very thin $3 \mathrm{D}$ objects, such as the cortical bone. Two diffusion equations are employed, and the orientations of the concentration gradients provide the orthotropic directions.

Based on the assumption that the osteons are mainly parallel to the external surface of the 3D structure, the first diffusion equation defines the evolution of the concentration $u_{3}$ and allows defining the vector $\nabla u_{3}$ across the thickness of the cortical domain $\Omega_{\text {cort }}$ :

$$
\begin{cases}c \operatorname{div}\left(\nabla u_{3}\right)=-\kappa h_{\text {spong }}, & \\ u_{3}=1 & \text { on } \partial \Omega_{\mathrm{ext}},\end{cases}
$$

where div is the divergence and $\nabla$ is the gradient, $c=10^{12}$, and the source term $-\kappa h_{\text {spong }}$, where $\kappa=10^{6}$, enables the introduction of a flow from the exterior to the interior of the femur. The concentration of $u_{3}$ across the femur is illustrated in Figure 1(b). The isosurfaces $u_{3}=$ const do not cross the outer boundary due to the maximum principle [Courant 1962], and they are parallel surfaces.

Thus, an approximate normalized vector $\boldsymbol{i}_{3}$ can be computed as

$$
i_{3} \simeq \frac{\nabla u_{3}}{\left\|\nabla u_{3}\right\|}
$$

with $\|\cdot\|$ the Euclidean norm of a vector. Assuming that in a 3D structure such as the femur there exists a strong relationship between the external loads and the directions of the osteons in the cortical bone [Wolff 1892], the second diffusion equation describes the evolution of the concentration $u_{10}$ and allows the description of the initial longitudinal direction $\nabla u_{10}$ :

$$
\begin{cases}\operatorname{div}\left[\left(a h_{\text {cort }}+b\right) \nabla u_{10}\right]=0, & \\ u_{10}=-2 & \text { on } \partial \Omega_{\mathrm{C}} \\ u_{10}=2.7 & \text { on } \partial \Omega_{\mathrm{H}} \\ u_{10}=0 & \text { on } \partial \Omega_{\mathrm{LT}} \\ u_{10}=1.8 & \text { on } \partial \Omega_{\mathrm{GT}}, \\ \frac{\partial u_{10}}{\partial \boldsymbol{n}}=0 & \text { everywhere else }\end{cases}
$$




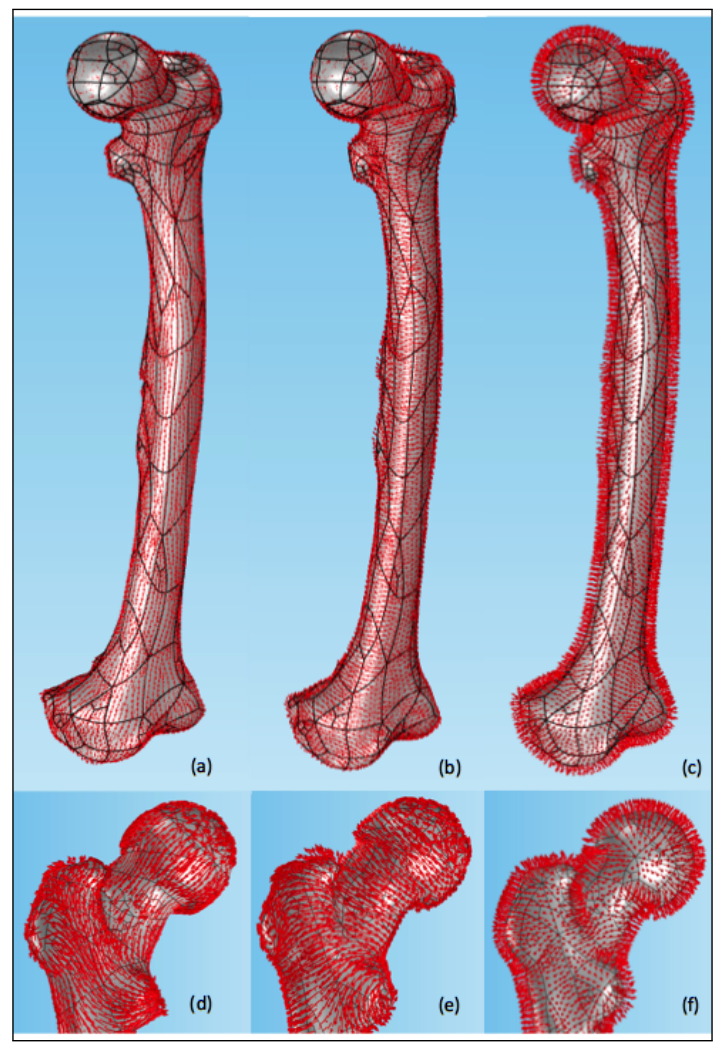

Figure 2. Numerical unit vectors $\boldsymbol{i}_{1}$ (left), $\boldsymbol{i}_{2}$ (center), and $\boldsymbol{i}_{3}$ (right). Anterior view of the femur (top), and posterior view of the upper femur (bottom).

where $a$ and $b$ are two constants that weight the influence of the spongy and the cortical bone. For our problem, $a \gg b$ (i.e., $a=10^{15}$ and $b=10^{11}$ ) to trigger a very high diffusion across the cortical domain $\Omega_{\text {cort }}$ and a very low diffusion in the

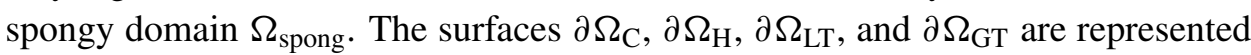
in Figure 1(c), with $\mathrm{C}$ indicating the condyles, and allow one to mimic the muscular anchoring surfaces at the extremities of the femur as has been done in [Huiskes et al. 1987; Doblaré and García 2001; Hambli et al. 2012]. A more accurate description of the directions of orthotropy, which are related to the distribution of the physiological stresses throughout the femur [Petrtýl et al. 1996], would require additional anchoring regions along the diaphysis [Duda et al. 1998]. It also has to be said that the values of the boundary conditions in (5) are not representative of the average physiological loads, but they have rather been optimized to best fit the $\mu \mathrm{CT}$ observations. The concentration of $u_{10}$ across the femur is shown in Figure 1(d). 


\begin{tabular}{|c|cccc|}
\hline$S_{i}$ & region & $h_{c}(\mathrm{~mm})$ & error & anisotropy mode \\
\hline$S_{1}$ & anterior diaphysis & & $19.3^{\circ}$ & orthotropy \\
$S_{2}$ & anterior diaphysis & $\approx 4.1$ & $11.5^{\circ}$ & orthotropy / transverse isotropy \\
$S_{4}$ & great trochanter & $\approx 0.8$ & $26.5^{\circ}$ & orthotropy \\
$S_{5}$ & great trochanter & $\approx 0.8$ & $21.1^{\circ}$ & orthotropy \\
$S_{8}$ & less trochanter & $\approx 2.5$ & $62.8^{\circ}$ & orthotropy \\
$S_{10}$ & neck & $\approx 0.7$ & $19.7^{\circ}$ & orthotropy \\
$S_{11}$ & neck & & $12.8^{\circ}$ & orthotropy \\
$S_{15}$ & posterior diaphysis & $\approx 5.3$ & $6.6^{\circ}$ & transverse isotropy \\
$S_{16}$ & posterior diaphysis & $\approx 5.7$ & $3.7^{\circ}$ & orthotropy / transverse isotropy \\
$S_{17}$ & posterior diaphysis & $\approx 6.1$ & $10.2^{\circ}$ & orthotropy / transverse isotropy \\
$S_{18}$ & posterior diaphysis & $\approx 6.0$ & $9^{\circ}$ & orthotropy / transverse isotropy \\
\hline
\end{tabular}

Table 1. Estimated error for the available cortical specimens $\left(h_{c}\right.$ is the cortical thickness). All specimens are cortical.

In the same spirit as for $\boldsymbol{i}_{3}$, we can compute the normalized longitudinal vector

$$
\boldsymbol{i}_{10} \simeq \frac{\nabla u_{10}}{\left\|\nabla u_{10}\right\|}
$$

By a simple cross product, we are able to obtain the circumferential vector

$$
\boldsymbol{i}_{2}=\frac{\boldsymbol{i}_{3} \wedge \boldsymbol{i}_{10}}{\left\|\boldsymbol{i}_{3} \wedge \boldsymbol{i}_{10}\right\|}
$$

We now have three vectors: the longitudinal $\left(\boldsymbol{i}_{10}\right)$, the circumferential $\left(\boldsymbol{i}_{2}\right)$, and the radial $\left(i_{3}\right)$. Nevertheless, to ensure the orthogonality of the basis, we need to recompute the longitudinal vector $\boldsymbol{i}_{10}$ to obtain

$$
i_{1}=\frac{i_{2} \wedge i_{3}}{\left\|i_{2} \wedge i_{3}\right\|}
$$

The diffusion equations are integrated over the 3D personalized geometry of the femur through a FE discretization.

\section{Results}

3.1. FE computation of the directions of orthotropy. The main objective of the FE model is to provide a good approximation of the field of orthotropic coordinates across the femur via the set of diffusion equations presented in Section 2.1.2. In Figure 2, we show the global trend of the three unit vectors $\boldsymbol{i}_{1}$ (longitudinal), $\boldsymbol{i}_{2}$ (circumferential), and $\boldsymbol{i}_{3}$ (radial).

In order to validate the numerical approach, a more precise comparison between the numerical and the experimental orthotropic directions is necessary. In [Cluzel 


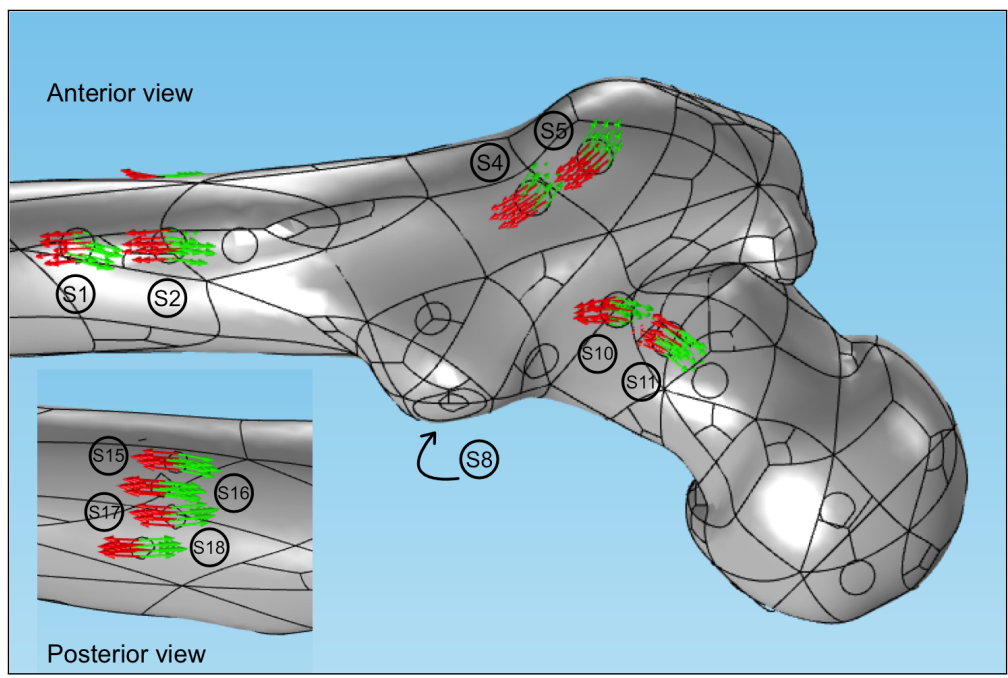

Figure 3. Comparison between the numerical longitudinal vector $\boldsymbol{i}_{1}$ (red arrows) and the measured vector $\boldsymbol{P}_{1}$ (green arrows) for specimens $S_{1}, S_{2}, S_{4}, S_{5}, S_{10}$, and $S_{11}$ on the anterior region of the femur and of $S_{15}$ to $S_{18}$ on the posterior region.

and Allena 2018] we have identified the projection $\boldsymbol{P}_{1}$ on the femur surface of the main direction of orthotropy. Then we have estimated the error between $\boldsymbol{P}_{1}$ and the numerical longitudinal vector $\boldsymbol{i}_{1}$ (Table 1).

For the comparison, we only consider the available cortical specimens from [Cluzel and Allena 2018, Table 1]: $S_{1}, S_{2}, S_{4}, S_{5}, S_{8}, S_{10}, S_{11}, S_{15}, S_{16}, S_{17}$, and $S_{18}$. In Figure 3, we show in red the vector $\boldsymbol{i}_{1}$ and in green the vector $\boldsymbol{P}_{1}$, except for $S_{8}$, which is on the other side of the femur.

Overall, the error goes from a minimal value of about $3.7^{\circ}$ for $S_{16}$ in the posterior diaphysis to a maximal value of about $62.8^{\circ}$ for $S_{8}$ in the less trochanter where a high gradient of the $\boldsymbol{i}_{1}$ is observed. However, in the anterior and posterior diaphysis, in the greater trochanter, and in the neck the error varies between $3.7^{\circ}$ and $26.5^{\circ}$.

\section{Discussion}

For an orthotropic material such as bone or a woven composite, the degradation mechanisms are oriented along the principal directions of the mesostructure. Therefore, in order to be able to correctly describe the mechanical as well as the damage behavior of such materials, the associated models need to be built with respect to the local systems of orthotropic coordinates. Nonetheless, if the orthotropic directions constantly change across the 3D geometry, their description becomes even more difficult. Then, being able to obtain an approximation of the orthotropic 
system of coordinates may constitute a numerical challenge, but it allows the simulation of the mechanical response of those structures for which the orthotropy plays a critical role.

In this article, we have proposed an FE technique based on the assumption that, for many heterogeneous structures, the main directions of the orthotropic behavior are determined by the external surface that shapes the geometry, except near the loading regions. This aspect can be easily observed in the case of a woven composite material where each wire is made of a large number of continuous fibers. However, it becomes more complex for biological materials (i.e., cortical and spongy bone), especially when the boundary conditions are applied over a large region of the structure [Duda et al. 1998].

Here we have employed our method to describe the field of orthotropic directions in a left human femur. The 3D geometry is obtained through a stack of CT images. Once the outer surface of the femur is accurately defined, the radial vector $\boldsymbol{i}_{3}$ across the thickness of the structure is computed using an appropriate diffusion equation. To obtain the longitudinal vector $\boldsymbol{i}_{10}$, a second diffusion equation is used which must take into account specific boundary conditions. As in [Huiskes et al. 1987; Doblaré and García 2001; Hambli et al. 2012] and for the sake of simplicity, such boundary conditions coincide with the main muscular anchoring regions (i.e., the head, the condyles, and the greater and the lesser trochanter). A sensibility study has been performed in order to confirm that the variation in intensity of the boundary conditions does not affect the final results. In fact, by increasing or decreasing by \pm 0.1 the values of $u_{10}$ in (5), successively, we found a variation of about $0.01^{\circ}$ in the main direction of orthotropy $\boldsymbol{i}_{1}$, which can be neglected. Such an approach provides a description of the orthonormal systems of orthotropic coordinates across the cortical bone. Nevertheless, in those regions where the thickness of the cortical bone is very thin (i.e., $h_{c}<0.5 \mathrm{~mm}$ ) or where the boundary conditions are applied, if $\boldsymbol{i}_{3}$ is properly determined, the longitudinal $\left(\boldsymbol{i}_{1}\right)$ and the circumferential $\left(\boldsymbol{i}_{2}\right)$ directions have no particular physical meaning.

In the literature, most of the numerical models describe cortical bone as an isotropic material due to several technical issues that one may encounter. A few orthotropic models have been proposed which include an orthotropic macroscale description of the bone behavior [Martínez-Reina et al. 2014; Taylor et al. 2002; Doblaré and García 2001; Gómez-Benito et al. 2005; Peng et al. 2006; Báča et al. 2008; Hambli et al. 2012; Ün and Çalık 2016]. Our approach allows a global and continuous representation of the orthotropic directions throughout the femur to be obtained while taking into account the local variations in specific regions of interest such as the neck and the lesser and greater trochanter.

In order to ensure the quality of the description of the orthotropic directions, some authors have measured in vitro the orthotropic field which has been manually 
implemented in the numerical models over about 20 regions in [Báča et al. 2007] and by cubes $2 \mathrm{~mm}$ in length in [Wirtz et al. 2003], for instance. In our approach, we rather estimate a posteriori the error between the numerical longitudinal vector $\boldsymbol{i}_{1}$ and the direction $\boldsymbol{P}_{1}$ identified via the $\mu \mathrm{CT}$ images [Cluzel and Allena 2018].

To conclude, the FE technique that we propose is globally consistent with the experimental data and allows one to obtain a proper approximation of the orthotropic field of coordinates. As in [Doblaré and García 2001], here we have assumed that the orthotropy directions are determined by both the applied boundary conditions and the external geometry of the femur. Additionally, only the boundary conditions at the extremities of the structure (i.e., the head, the greater and lesser trochanter, and the condyles) have been considered at this stage. Nonetheless, further muscular anchoring surfaces should be taken into account in the thicker diaphysis region [Duda et al. 1998], which may lead to slight rotations of the osteons with respect to the longitudinal axis, as observed in [Petrtýl et al. 1996; Báča et al. 2007]. To detect such variations, we are currently acquiring additional measurements along the diaphysis in order to obtain a more complete map of the osteons' orientation. Then we will build corrective functions to adjust both the numerical axial $\left(\boldsymbol{i}_{1}\right)$ and circumferential $\left(\boldsymbol{i}_{2}\right)$ unit vectors in the diaphysis via a rotation around $\boldsymbol{i}_{3}$. We envisage undertaking a series of simulations for different types of loading on the femur to quantify the precision needed for positioning the coordinates systems. We expect to find some differences in the failure mechanisms of the orthotropic damage model rather than on the global displacements. Taking into account the exact anisotropic directions of the cortical bone microstructure will allow one to rigorously describe the damage model. This constitutes a fundamental element to describe the overall remodeling process, including the evolution in time of the anisotropic directions [Placidi et al. 2004], and more specifically the interplay between the biological and the mechanical processes involved [Frame et al. 2017; Schmitt et al. 2016].

\section{Acknowledgement}

The authors are grateful to the ParisTech BiomecAM chair program on subjectspecific musculoskeletal modeling for partial funding of the work.

\section{References}

[Allena and Aubry 2011] R. Allena and D. Aubry, "A novel technique to parametrize shell-like deformations inside biological membranes", Comput. Mech. 47:4 (2011), 409-423.

[Báča et al. 2007] V. Báča, D. Kachlík, Z. Horák, and J. Stingl, "The course of osteons in the compact bone of the human proximal femur with clinical and biomechanical significance", Surg. Radiol. Anat. 29:3 (2007), 201-207. 
[Báča et al. 2008] V. Báča, Z. Horák, P. Mikulenka, and V. Džupa, "Comparison of an inhomogeneous orthotropic and isotropic material models used for FE analyses", Med. Eng. Phys. 30:7 (2008), 924-930.

[Bernard et al. 2013] S. Bernard, Q. Grimal, and P. Laugier, "Accurate measurement of cortical bone elasticity tensor with resonant ultrasound spectrosco", J. Mech. Behav. Biomed. 18 (2013), 12-19.

[Bessho et al. 2009] M. Bessho, I. Ohnishi, T. Matsumoto, S. Ohashi, J. Matsuyama, K. Tobita, M. Kaneko, and K. Nakamura, "Prediction of proximal femur strength using a CT-based nonlinear finite element method: differences in predicted fracture load and site with changing load and boundary conditions", Bone 45:2 (2009), 226-231.

[Cluzel and Allena 2015] C. Cluzel and R. Allena, "Modelling of anisotropic cortical bone based on degradation mechanism”, Comput. Method. Biomech. 18:S1 (2015), 1914-1915.

[Cluzel and Allena 2018] C. Cluzel and R. Allena, "Heterogeneous directions of orthotropy in three dimensional structures: geometrical identification from $\mu \mathrm{CT}$ images", preprint, 2018.

[Courant 1962] R. Courant, Methods of mathematical physics, vol. II: Partial differential equations, Wiley-VCH, 1962.

[Cowin and He 2005] S. C. Cowin and Q.-C. He, "Tensile and compressive stress yield criteria for cancellous bone", J. Biomech. 38:1 (2005), 141-144.

[Doblaré and García 2001] M. Doblaré and J. M. García, "Application of an anisotropic boneremodelling model based on a damage-repair theory to the analysis of the proximal femur before and after total hip replacement", J. Biomech. 34:9 (2001), 1157-1170.

[Doblaré et al. 2004] M. Doblaré, J. M. García, and M. J. Gómez, "Modelling bone tissue fracture and healing: a review", Eng. Fract. Mech. 71:13-14 (2004), 1809-1840.

[Duchemin et al. 2008] L. Duchemin, V. Bousson, C. Raossanaly, C. Bergot, J. D. Laredo, W. Skalli, and D. Mitton, "Prediction of mechanical properties of cortical bone by quantitative computed tomography", Med. Eng. Phys. 30:3 (2008), 321-328.

[Duda et al. 1998] G. N. Duda, M. Heller, J. Albinger, O. Schulz, E. Schneider, and L. Claes, "Influence of muscle forces on femoral strain distribution”, J. Biomech. 31:9 (1998), 841-846.

[Frame et al. 2017] J. Frame, P.-Y. Rohan, L. Corté, and R. Allena, "A mechano-biological model of multi-tissue evolution in bone", Continuum Mech. Therm. (online publication December 2017).

[García et al. 2001] J. M. García, M. A. Martinez, and M. Doblaré, "An anisotropic internal-external bone adaptation model based on a combination of CAO and continuum damage mechanics technologies", Comput. Method. Biomech. 4:4 (2001), 355-377.

[Gómez-Benito et al. 2005] M. J. Gómez-Benito, J. M. García-Aznar, and M. Doblaré, "Finite element prediction of proximal femoral fracture patterns under different loads", J. Biomech. Eng. 127:1 (2005), 9-14.

[Hambli et al. 2012] R. Hambli, A. Bettamer, and S. Allaoui, "Finite element prediction of proximal femur fracture pattern based on orthotropic behaviour law coupled to quasi-brittle damage", Med. Eng. Phys. 34:2 (2012), 202-210.

[Herman et al. 2010] B. C. Herman, L. Cardoso, R. J. Majeska, K. J. Jepsen, and M. B. Schaffler, "Activation of bone remodeling after fatigue: differential response to linear microcracks and diffuse damage", Bone 47:4 (2010), 766-772.

[Huiskes et al. 1987] R. Huiskes, H. Weinans, H. J. Grootenboer, M. Dalstra, B. Fudala, and T. J. Slooff, "Adaptive bone-remodeling theory applied to prosthetic-design analysis", J. Biomech. 20:1112 (1987), 1135-1150.

[Martínez-Reina et al. 2014] J. Martínez-Reina, I. Reina, J. Domínguez, and J. M. García-Aznar, "A bone remodelling model including the effect of damage on the steering of BMUs", J. Mech. Behav. Biomed. 32 (2014), 99-112. 
[O'Brien et al. 2007] F. J. O’Brien, D. Taylor, and T. C. Lee, "Bone as a composite material: the role of osteons as barriers to crack growth in compact bone”, Int. J. Fatigue 29:6 (2007), 1051-1056.

[Peng et al. 2006] L. Peng, J. Bai, X. Zeng, and Y. Zhou, "Comparison of isotropic and orthotropic material property assignments on femoral finite element models under two loading conditions", Med. Eng. Phys. 28:3 (2006), 227-233.

[Petrtýl et al. 1996] M. Petrtýl, J. Heřt, and P. Fiala, "Spatial organization of the haversian bone in man", J. Biomech. 29:2 (1996), 161-169.

[Placidi et al. 2004] L. Placidi, S. H. Faria, and K. Hutter, "On the role of grain growth, recrystallization and polygonization in a continuum theory for anisotropic ice sheets", Ann. Glaciol. 39 (2004), 49-52.

[Rémond et al. 2016] Y. Rémond, S. Ahzi, M. Baniassadi, and H. Garmestani, Applied RVE reconstruction and homogenization of heterogeneous materials, Wiley, 2016.

[Rho 1996] J.-Y. Rho, "An ultrasonic method for measuring the elastic properties of human tibial cortical and cancellous bone", Ultrasonics 34:8 (1996), 777-783.

[Rho et al. 1998] J.-Y. Rho, L. Kuhn-Spearing, and P. Zioupos, "Mechanical properties and the hierarchical structure of bone", Med. Eng. Phys. 20:2 (1998), 92-102.

[Schmitt et al. 2016] M. Schmitt, R. Allena, T. Schouman, S. Frasca, J. M. Collombet, X. Holy, and P. Rouch, "Diffusion model to describe osteogenesis within a porous titanium scaffold", Comput. Method. Biomech. 19:2 (2016), 171-179.

[Seref-Ferlengez et al. 2015] Z. Seref-Ferlengez, O. D. Kennedy, and M. B. Schaffler, "Bone microdamage, remodeling and bone fragility: how much damage is too much damage?", BoneKEy Rep. 4 (2015), 644.

[Spingarn et al. 2017] C. Spingarn, D. Wagner, Y. Rémond, and D. George, "Multiphysics of bone remodeling: a 2D mesoscale activation simulation", Med. Eng. Phys. 28:S1 (2017), 153-158.

[Taylor et al. 2002] W. R. Taylor, E. Roland, H. Ploeg, D. Hertig, R. Klabunde, M. D. Warner, M. C. Hobatho, L. Rakotomanana, and S. E. Clift, "Determination of orthotropic bone elastic constants using FEA and modal analysis", J. Biomech. 35:6 (2002), 767-773.

[Tsai and Wu 1971] S. W. Tsai and E. M. Wu, "A general theory of strength for anisotropic materials", J. Compos. Mater. 5:1 (1971), 58-80.

[Ün and Çalık 2016] K. Ün and A. Çalık, "Relevance of inhomogeneous-anisotropic models of human cortical bone: a tibia study using the finite element method", Biotechnol. Biotec. Eq. 30:3 (2016), 538-547.

[Ural and Vashishth 2007] A. Ural and D. Vashishth, "Anisotropy of age-related toughness loss in human cortical bone: a finite element study", J. Biomech. 40:7 (2007), 1606-1614.

[Vashishth 2007] D. Vashishth, "Hierarchy of bone microdamage at multiple length scales", Int. J. Fatigue 29:6 (2007), 1024-1033.

[Wasserman et al. 2008] N. Wasserman, B. Brydges, S. Searles, and O. Akkus, "In vivo linear microcracks of human femoral cortical bone remain parallel to osteons during aging", Bone 43:5 (2008), 856-861.

[Wirtz et al. 2003] D. C. Wirtz, T. Pandorf, F. Portheine, K. Radermacher, N. Schiffers, A. Prescher, D. Weichert, and F. U. Niethard, "Concept and development of an orthotropic FE model of the proximal femur”, J. Biomech. 36:2 (2003), 289-293.

[Wolff 1892] J. Wolff, Das Gesetz der Transformation der Knochen, Hirschwald, 1892.

Received 9 Apr 2018. Revised 14 Jun 2018. Accepted 25 Jun 2018. 
RACHELE ALLENA: rachele.allena@ensam.eu

Institute de Biomécanique Humaine George Charpak, Arts et Métiers ParisTech, Paris, France

CHRISTOPHE CLUZEL: cluzel@lmt.ens-cachan.fr

Laboratoire de Mécanique et Technologie, Ecole Normale Supérieure Paris Saclay, Cachan, France and

Département Science et Genie des Materiaux, Institut Universitaire de Technologie d'Evry Val d'Essonne, Every, France 
EDITORIAL BOARD

ANTONIO CARCATERRA

ERIC A. CARLEN

FRANCESCO DELL'ISOLA

RAFFAELE ESPOSITO

ALBERT FANNJIANG

Gilles A. FrancFort

PieRANGelo MARCATI

JEAN-JACQUES MARIGO

PETER A. MARKOWICH

MARTIN OSTOJA-STARZEWSKI

PIERRE SEPPECHER

DAVID J. STEIGMANN

PAUl STEINMANN

PierRe M. SuQueT

MANAGING EDITORS

MICOL AMAR

CORRADO LATTANZIO

ANGELA MADEO

MARTIN OSTOJA-STARZEWSKI

ADVISORY BOARD

ADNAN AKAY

Holm AltenbaCH

MICOL AMAR

HARM ASKES

TEODOR ATANACKOVIĆ

VICTOR BERDICHEVSKY

GUY BOUCHITTÉ

ANDREA BRAIDES

ROBERTO CAMASSA

MAURO CARFORE

ERIC DARVE

FELIX DARVE

ANNA DE MASI

GianPiETRo DEL PIERo

EMmANUELE Di BENEDETTO

BERNOLD FIEDLER

IRENE M. GAMBA

DAVID Y. GAO

SERGEY GAVRILYUK

Timothy J. HEALEY

DOMINIQUE JEULIN

ROGER E. KHAYAT

CORRADO LATTANZIO

ROBERT P. LIPTON

ANGELO LUONGO

ANGELA MADEO

JUAN J. MANFREDI

CARlo MARCHIORO

ROBERTO NATALINI

PATRIZIO NEFF

ANDREY PIATNITSKI

ERRICO PRESUTtI

MARIO PULVIRENTI

LuCiO RuSSO

Miguel A. F. SANJUAN

PATRICK SElVAdURAI

ALEXANDER P. SEYRANIAN

MiroslaV ŠILHAVÝ

GUIDO SWEERS

ANTOINETTE TORDESILLAS

LEV TRUSKINOVSKY

JUAN J. L. VELÁZQUEZ

VINCENZO VESPRI

ANGELO VULPIANI msp.org/memocs

Università di Roma "La Sapienza", Italia

Rutgers University, USA

(CO-CHAIR) Università di Roma "La Sapienza", Italia

(TREASURER) Università dell'Aquila, Italia

University of California at Davis, USA

(CO-CHAIR) Université Paris-Nord, France

Università dell' Aquila, Italy

École Polytechnique, France

DAMTP Cambridge, UK, and University of Vienna, Austria

(CHAIR MANAGING EDITOR) Univ. of Illinois at Urbana-Champaign, USA

Université du Sud Toulon-Var, France

University of California at Berkeley, USA

Universität Erlangen-Nürnberg, Germany

LMA CNRS Marseille, France

Università di Roma "La Sapienza", Italia

Università dell' Aquila, Italy

Université de Lyon-INSA (Institut National des Sciences Appliquées), France

(CHAIR MANAGING EDITOR) Univ. of Illinois at Urbana-Champaign, USA

Carnegie Mellon University, USA, and Bilkent University, Turkey

Otto-von-Guericke-Universität Magdeburg, Germany

Università di Roma "La Sapienza", Italia

University of Sheffield, UK

University of Novi Sad, Serbia

Wayne State University, USA

Université du Sud Toulon-Var, France

Università di Roma Tor Vergata, Italia

University of North Carolina at Chapel Hill, USA

Università di Pavia, Italia

Stanford University, USA

Institut Polytechnique de Grenoble, France

Università dell'Aquila, Italia

Università di Ferrara and International Research Center MEMOCS, Italia

Vanderbilt University, USA

Freie Universität Berlin, Germany

University of Texas at Austin, USA

Federation University and Australian National University, Australia

Université Aix-Marseille, France

Cornell University, USA

École des Mines, France

University of Western Ontario, Canada

Università dell' Aquila, Italy

Louisiana State University, USA

Università dell'Aquila, Italia

Université de Lyon-INSA (Institut National des Sciences Appliquées), France University of Pittsburgh, USA

Università di Roma "La Sapienza", Italia

Istituto per le Applicazioni del Calcolo "M. Picone", Italy

Universität Duisburg-Essen, Germany

Narvik University College, Norway, Russia

Università di Roma Tor Vergata, Italy

Università di Roma "La Sapienza", Italia

Università di Roma "Tor Vergata”, Italia

Universidad Rey Juan Carlos, Madrid, Spain

McGill University, Canada

Moscow State Lomonosov University, Russia

Academy of Sciences of the Czech Republic

Universität zu Köln, Germany

University of Melbourne, Australia

École Polytechnique, France

Bonn University, Germany

Università di Firenze, Italia

Università di Roma La Sapienza, Italia

MEMOCS (ISSN 2325-3444 electronic, 2326-7186 printed) is a journal of the International Research Center for the Mathematics and Mechanics of Complex Systems at the Università dell'Aquila, Italy.

Cover image: "Tangle" by @ John Horigan; produced using the Context Free program (contextfreeart.org).

\section{PUBLISHED BY}

mathematical sciences publishers nonprofit scientific publishing

http://msp.org/

(C) 2018 Mathematical Sciences Publishers 
Mathematics and Mechanics of Complex Systems vol. 6 no. 4

A model for interfaces and its mesoscopic limit

Michele Aleandri and Venanzio Di Giulio

Optimal orthotropy and density distribution of two-dimensional structures

Narindra Ranaivomiarana, François-Xavier Irisarri, Dimitri

Bettebghor and Boris Desmorat

A multiphysics stimulus for continuum mechanics bone remodeling 307

Daniel George, Rachele Allena and Yves Rémond

On linear non-local thermo-viscoelastic waves in fluids

Joe D. Goddard

Heterogeneous directions of orthotropy in three-dimensional

structures: finite element description based on diffusion equations

Rachele Allena and Christophe Cluzel

A general method for the determination of the local orthotropic directions of heterogeneous materials: application to bone structures using $\mu \mathrm{CT}$ images

Christophe Cluzel and Rachele Allena

MEMOCS is a journal of the International Research Center for the Mathematics and Mechanics of Complex Systems at the Università dell' Aquila, Italy.

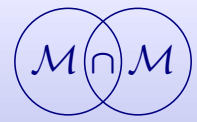


EDITORIAL BOARD

ANTONIO CARCATERRA

ERIC A. CARLEN

FRANCESCO DELL'ISOLA

RAFFAELE ESPOSITO

ALBERT FANNJIANG

Gilles A. FrancFort

PieRANGelo MARCATI

JEAN-JACQUES MARIGO

PETER A. MARKOWICH

MARTIN OSTOJA-STARZEWSKI

PIERRE SEPPECHER

DAVID J. STEIGMANN

PAUl STEINMANN

PierRe M. SuQueT

MANAGING EDITORS

MICOL AMAR

CORRADO LATTANZIO

ANGELA MADEO

MARTIN OSTOJA-STARZEWSKI

ADVISORY BOARD

ADNAN AKAY

Holm AltenbaCH

MICOL AMAR

HARM ASKES

TEODOR ATANACKOVIĆ

VICTOR BERDICHEVSKY

GUY BOUCHITTÉ

ANDREA BRAIDES

ROBERTO CAMASSA

MAURO CARFORE

ERIC DARVE

FELIX DARVE

ANNA DE MASI

GianPiETRo DEL PIERo

EMmANUELE Di BENEDETTO

BERNOLD FIEDLER

IRENE M. GAMBA

DAVID Y. GAO

SERGEY GAVRILYUK

Timothy J. HEALEY

DOMINIQUE JEULIN

ROGER E. KHAYAT

CORRADO LATTANZIO

ROBERT P. LIPTON

ANGELO LUONGO

ANGELA MADEO

JUAN J. MANFREDI

CARlo MARCHIORO

ROBERTO NATALINI

PATRIZIO NEFF

ANDREY PIATNITSKI

ERRICO PRESUTtI

MARIO PULVIRENTI

LuCiO RuSSO

Miguel A. F. SANJUAN

PATRICK SElVAdURAI

ALEXANDER P. SEYRANIAN

MiroslaV ŠILHAVÝ

GUIDO SWEERS

ANTOINETTE TORDESILLAS

LEV TRUSKINOVSKY

JUAN J. L. VELÁZQUEZ

VINCENZO VESPRI

ANGELO VULPIANI msp.org/memocs

Università di Roma "La Sapienza", Italia

Rutgers University, USA

(CO-CHAIR) Università di Roma "La Sapienza", Italia

(TREASURER) Università dell'Aquila, Italia

University of California at Davis, USA

(CO-CHAIR) Université Paris-Nord, France

Università dell' Aquila, Italy

École Polytechnique, France

DAMTP Cambridge, UK, and University of Vienna, Austria

(CHAIR MANAGING EDITOR) Univ. of Illinois at Urbana-Champaign, USA

Université du Sud Toulon-Var, France

University of California at Berkeley, USA

Universität Erlangen-Nürnberg, Germany

LMA CNRS Marseille, France

Università di Roma "La Sapienza", Italia

Università dell' Aquila, Italy

Université de Lyon-INSA (Institut National des Sciences Appliquées), France

(CHAIR MANAGING EDITOR) Univ. of Illinois at Urbana-Champaign, USA

Carnegie Mellon University, USA, and Bilkent University, Turkey

Otto-von-Guericke-Universität Magdeburg, Germany

Università di Roma "La Sapienza", Italia

University of Sheffield, UK

University of Novi Sad, Serbia

Wayne State University, USA

Université du Sud Toulon-Var, France

Università di Roma Tor Vergata, Italia

University of North Carolina at Chapel Hill, USA

Università di Pavia, Italia

Stanford University, USA

Institut Polytechnique de Grenoble, France

Università dell'Aquila, Italia

Università di Ferrara and International Research Center MEMOCS, Italia

Vanderbilt University, USA

Freie Universität Berlin, Germany

University of Texas at Austin, USA

Federation University and Australian National University, Australia

Université Aix-Marseille, France

Cornell University, USA

École des Mines, France

University of Western Ontario, Canada

Università dell' Aquila, Italy

Louisiana State University, USA

Università dell'Aquila, Italia

Université de Lyon-INSA (Institut National des Sciences Appliquées), France University of Pittsburgh, USA

Università di Roma "La Sapienza", Italia

Istituto per le Applicazioni del Calcolo "M. Picone", Italy

Universität Duisburg-Essen, Germany

Narvik University College, Norway, Russia

Università di Roma Tor Vergata, Italy

Università di Roma "La Sapienza", Italia

Università di Roma "Tor Vergata”, Italia

Universidad Rey Juan Carlos, Madrid, Spain

McGill University, Canada

Moscow State Lomonosov University, Russia

Academy of Sciences of the Czech Republic

Universität zu Köln, Germany

University of Melbourne, Australia

École Polytechnique, France

Bonn University, Germany

Università di Firenze, Italia

Università di Roma La Sapienza, Italia

MEMOCS (ISSN 2325-3444 electronic, 2326-7186 printed) is a journal of the International Research Center for the Mathematics and Mechanics of Complex Systems at the Università dell'Aquila, Italy.

Cover image: "Tangle" by @ John Horigan; produced using the Context Free program (contextfreeart.org).

\section{PUBLISHED BY}

mathematical sciences publishers nonprofit scientific publishing

http://msp.org/

(C) 2018 Mathematical Sciences Publishers 
Mathematics and Mechanics of Complex Systems vol. 6 no. 4

A model for interfaces and its mesoscopic limit

Michele Aleandri and Venanzio Di Giulio

Optimal orthotropy and density distribution of two-dimensional structures

Narindra Ranaivomiarana, François-Xavier Irisarri, Dimitri

Bettebghor and Boris Desmorat

A multiphysics stimulus for continuum mechanics bone remodeling 307

Daniel George, Rachele Allena and Yves Rémond

On linear non-local thermo-viscoelastic waves in fluids

Joe D. Goddard

Heterogeneous directions of orthotropy in three-dimensional

structures: finite element description based on diffusion equations

Rachele Allena and Christophe Cluzel

A general method for the determination of the local orthotropic directions of heterogeneous materials: application to bone structures using $\mu \mathrm{CT}$ images

Christophe Cluzel and Rachele Allena

MEMOCS is a journal of the International Research Center for the Mathematics and Mechanics of Complex Systems at the Università dell' Aquila, Italy.

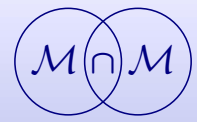

